Tropical Journal of Pharmaceutical Research September 2019; 18 (9): 1935-1941

ISSN: 1596-5996 (print); 1596-9827 (electronic)

(1) Pharmacotherapy Group, Faculty of Pharmacy, University of Benin, Benin City, 300001 Nigeria.

\title{
Effect of $\alpha$-momordicine on proliferation and apoptosis of liver cancer, and its associated mechanisms of action
}

\author{
Mei Yang ${ }^{1}$, Wen Jin ${ }^{1}$, Wei Shi ${ }^{1}$, Bo Wang ${ }^{1}$, Qing $\mathrm{Li}^{2}$, Chunfeng Guan ${ }^{2 *}$ \\ ${ }^{1}$ Department of Medicine, Tongling Vocational and Technical College, 678 Furong Road, Hefei Economic Development Zone, \\ Anhui Province, ${ }^{2}$ Department of Obstetrics and Gynecology, Second Affiliated Hospital of Anhui Medical University, Hefei, \\ Anhui Province, China
}

*For correspondence: Email: xvk88f@163.com

Sent for review: 4 July 2019

Revised accepted: 29 August 2019

\begin{abstract}
Purpose: To investigate the effect of $\alpha$-momordicine $(\alpha-M M C)$ on liver cancer cell proliferation and apoptosis, and to elucidate the mechanisms of action involved.

Methods: In in vitro experiments, hepatoma cell lines were used, while nude mice with hepatocellular carcinoma were used for in vivo studies. Cancer cell proliferation was determined using MTT assay while apoptosis was assayed by flow cytometry and TUNNEL staining. Gene expression was determined with real-time polymerase chain reaction (RT-PCR), while protein expression levels were assayed by Western blot, immunohistochemistry and immunofluorescence.

Results: Alpha-MMC decreased HCC cell viability dose-dependently ( $p<0.05)$. In HepG2 cells, G2/M cell cycle was halted after $48 \mathrm{~h}$ intervention with $1.24 \mathrm{mg} / \mathrm{mL} \alpha-M M C$. However, at G0/G1 phase, $\alpha$ $M M C$ at doses of 1.06 and $0.92 \mathrm{mg} / \mathrm{mL}$ caused cell cycle arrest of HCC-LM3 and SMMC-7721 cells. In vivo studies showed that after establishment of the nude mice liver cancer model, exposure to $\alpha-M M C$ at a dose of $0.70 \mathrm{mg} / \mathrm{kg}$ or $2.08 \mathrm{mg} / \mathrm{kg}$ for 4 weeks reduced the size of liver cancer in the treatment group, relative to control group; mean diameter of liver cancer decreased from 2.16 to $0.51 \mathrm{~cm}$, while mean volume decreased from 1.185 to $0.085 \mathrm{~cm}^{3}$. Moreover, $\alpha-M M C$ increased apoptosis level in liver cancer tissues in nude mice, and down-regulated the expressions of P-AKT, RAGE, MMP-9 and HMGB1, but upregulated Bax/Bcl2 ratio $(p<0.05)$.

Conclusion: $\alpha-M M C$ inhibits cancer cell growth and proliferation, and facilitates their apoptosis by positively regulating the ratio of Bax/Bcl2. The anti-liver cancer effect of $\alpha-M M C$ is mediated via HMGB1-RAGE and AKT signaling pathways.
\end{abstract}

Keywords: $\alpha$-Momordicine, Liver cancer, Proliferation, Apoptosis

This is an Open Access article that uses a fund-ing model which does not charge readers or their institutions for access and distributed under the terms of the Creative Commons Attribution License (http://creativecommons.org/licenses/by/4.0) and the Budapest Open Access Initiative (http://www.budapestopenaccessinitiative.org/read), which permit unrestricted use, distribution, and reproduction in any medium, provided the original work is properly credited.

Tropical Journal of Pharmaceutical Research is indexed by Science Citation Index (SciSearch), Scopus, International Pharmaceutical Abstract, Chemical Abstracts, Embase, Index Copernicus, EBSCO, African Index Medicus, JournalSeek, Journal Citation Reports/Science Edition, Directory of Open Access Journals (DOAJ), African Journal Online, Bioline International, Open-J-Gate and Pharmacy Abstracts

\section{INTRODUCTION}

Hepatocellular carcinoma (HCC) is a prevalent cancer all over the world. The pathogenesis of liver cancer is not yet clearly understood, but it may be related to gene mutation, infection, immune damage and other factors [1]. Studies have shown that the 5-year survival for advanced liver cancer is extremely low. Radical resection of early liver cancer increases the 5-year survival to more than $60 \%$, but $60-70 \%$ of patients still have metastasis and recurrence [2]. Hence, new 
treatments are needed to extend patients' survival.

$\alpha$-Momorcharin ( $\alpha$-MMC) is a ribosomal inactivation protein extracted from bitter melon seeds. It hydrolyzes the $\mathrm{N}-\mathrm{C}$ glycoside bond between adenine base and ribosome at position A4324 of ribosomal 28SrRNA in eukaryotic cells, and prevents the binding of elongator EF-2 to ribosome, thereby inhibiting protein synthesis [3]. Studies have shown that $\alpha$-MMC exerts immuneregulatory effects on breast carcinoma, colorectal carcinoma, hepatoma, non-small cell lung cancer, epithelial cell cancer and glioma [4-6]. The effect of $\alpha$-MMC on apoptosis and proliferation of hepatoma cells has been rarely reported. It has been reported that $\alpha-\mathrm{MMC}$ may induce hepatocyte apoptosis through low density lipoprotein receptor related protein 1 (LRP1)mediated Jun N-terminal kinase (JNK) signaling pathway [7].

Receptor of advanced glycosylation end products (RAGE) and high-mobility group Box1 (HMGB1) participate in the proliferation, invasion, migration and apoptosis of liver cancer cells, and are the potential therapeutic targets of HCC [8]. Protein kinase $B$ (AKT) is also important for the apoptosis and proliferation of HCC cells [9].This study investigated the influence of $\alpha$-MMC on HCC proliferation and apoptosis, and its effect on HMGB1, AKT and RAGE expression levels was determined so as to unravel the mechanism involved in the anti-HCC effect of $\alpha$-MMC.

\section{EXPERIMENTAL}

\section{Cells and culture}

The liver cancer cells (SMMC-7721, HepG2, and HCC-LM3; Shanghai Yaji Biotechnology Co., Ltd.) were cultured in DMEM-1640 medium (Zhengzhou Chuangsheng Bioengineering Co. Ltd.) containing $10 \%$ fetal bovine serum at $5 \%$ $\mathrm{CO}_{2}$ and $37^{\circ} \mathrm{C}$. Passage was carried out with $0.25 \%$ trypsin. The cells used in this experiment were passage 3 cells.

\section{Evaluation of effect of $\alpha-M M C$ on proliferative potential}

The hepatoma cell lines were incubated in at a concentration of $2 \times 10^{4}$ cells per well, and treated with different doses of $\alpha$-MMC (0.45, $0.60,0.75,0.90,1.05,1.20,1.35$ and 1.50 $\mathrm{mg} / \mathrm{mL}$ ) [6]. The $\alpha$-MMC was obtained from Shanghai Beizhuo Biotechnology Co. Ltd. Untreated cells served as control. Cell proliferation was measured using MTT kit (Shanghai Gefan Biotechnology Co. Ltd.) with absorbance readings obtained at $450 \mathrm{~nm}$ in a Rebec microplate reader.

\section{Flow cytometry}

Detection of apoptosis was done using flow cytometry (BD, USA), and Annexin V-FITC/PI apoptosis assay kit (Aimei Technology Co. Ltd). Apoptosis in the hepatoma cells was analyzed. Cell cycle analysis was performed flow cytometrically, and the proportions of early and late apoptotic cells were calculated using Modfit LT software.

\section{TUNNEL staining for determination of apoptosis in tumor tissues}

Liver cancer tissue was placed in paraformaldehyde for $24 \mathrm{~h}$, and after dehydration and transparency, it was embedded in paraffin. The thickness of unbroken section was 4 to 6 $\mathrm{mm}$. Sodium citrate $(0.1 \mathrm{~mol} / \mathrm{L}, 200 \mathrm{~mL})$ was heated in a microwave for $5 \mathrm{~min}$, and the slices were taken out and immersed in distilled water. The TUNNEL test was performed using an in situ apoptosis kit. Positive staining was depicted as brown color. The number of apoptotic cells was counted.

\section{RT-PCR}

The levels of expression of $\mathrm{Bcl} 2$, Bax, matrix metalloprotein-9 (MMP9), HMGB1, and RAGE mRNA were assayed with PT-PCR. The primers sequences used are shown in Table 1.

Table 1: Primers sequences

\begin{tabular}{lll}
\hline & \multicolumn{1}{l}{ Upstream } & Downstream \\
\cline { 2 - 3 } Bcl-2 & 5'-CATGTGTGTGGAGAGCGTCAA-3' & 5'-GCCGGTTCAGGTACTCAGTCA-3' \\
MMP9 & 5'-CGTCGTGATCCCCACTTACTATGGAAACTC-3' & 5'-GCAGAAGCCATACAGTTTATCCTGGTCATA-3' \\
Bax & 5'-GATCCAGGATCGAGCAGA-3' & 5'-AAGTAGAAGAGGGCAACCAC-3' \\
HMGB1 & 5'-CGGATGCTTCTGTCAACTTCT-3' & 5'-AGTTTCTTCGCAACATCACCA-3' \\
RAGE & 5'-CGGCTGGTGTTCCCAATAA-3' & 5'-TGTTCCTTCACAGATACTCCCT-3' \\
B-Actin & 5'-CTGGAACGGTGAAGGTGACA-3' & 5'-AAGGGACTTCCTGTAACAATGCA-3' \\
\hline
\end{tabular}


The test kits were purchased from Shenggong Bioengineering (Shanghai) Co. Ltd. Extraction of total RNA was done using Trizol reagent, and RT-PCR was carried out after reverse transcription. The primer sequences were designed by Shanghai Bioengineering Co. Ltd. Each sample was assayed at least 3 times in a set of 3 duplicate wells. The RT-PCR reaction conditions were: $30 \mathrm{sec}$ pre-denaturation at 95 ${ }^{\circ} \mathrm{C}, 5 \mathrm{sec}$ PCR reaction at $95{ }^{\circ} \mathrm{C}, 60^{\circ} \mathrm{C}$ for 30 $\mathrm{sec}$, and a total of 40 cycles.

\section{Western blot assay}

The expression levels of BCL2, Bax, HMGB, pAKT, AKT and MMP9 were assayed with Western blotting. The antibodies were purchased from Santa Cruz Biotechnology, Inc., USA. The proteins were denatured by boiling with SDS buffer for $5 \mathrm{~min}$. Then, SDS-polyacrylamide gel electrophoresis was followed by transfer of the proteins to PVDF membranes, sealing with $5 \%$ skim milk powder, and overnight incubation with the primary antibodies at $4{ }^{\circ} \mathrm{C}$. Thereafter, the membrane was washed 3 times, each for $5 \mathrm{~min}$, and incubated with secondary antibody for $2 \mathrm{~h}$ at $37^{\circ} \mathrm{C}$. The membrane was then washed 3 times with TBST. The blots were visualized with enhanced chemiluminescence (ECL), with $\beta$ actin as reference, and the ratio of the target protein band gray scale to that of $\beta$-actin was calculated.

\section{Establishment and treatment of liver cancer models}

Four-week-old nude mice were purchased from Shanghai Yusen Biotechnology Co. Ltd from 2006 to 2009. The feeding environment temperature was $22 \pm 2^{\circ} \mathrm{C}$, humidity was $50 \pm 10$ $\%$, with 12-h dark/12-h light photoperiod. The mice were permitted ad libitum access to feed and clean water. The HCC-LM3 cells were maintained in $0.1 \mathrm{~L}$ of DMEM: F12 $(1: 1, \mathrm{v}$ : v) serum-free medium. The nude mice were anesthetized with $2 \%$ pentobarbital $(45 \mathrm{mg} / \mathrm{kg})$.

After laparotomy, the liver of 30 mice were subjected to inoculation with the cancer cells. The mice were subsequently checked at 3-day intervals (total monitoring period was 4 weeks and 2 days.

Thereafter, the animals were assigned to 3 groups. One group was intraperitoneally injected $\alpha-M M C$ at a dose of $2.08 \mathrm{mg} / \mathrm{kg}$. Another group was intraperitoneally injected $\alpha-M M C$ at a dose of $0.70 \mathrm{mg} / \mathrm{kg}$, while a third group was intraperitoneally injected an equivalent volume of normal saline; all treatments lasted for 4 weeks [10]. The nude mice were sacrificed via cervical dislocation and the tumor size was measured with a Vernier caliper. Ethical approval for the animal experiment was obtained from the Second Affiliated Hospital of Anhui Medical University (approval no. $=$ DE2018008). Animal handling was in accordance with the U.K. Animals (Scientific Procedures) Act, 1986 and associated guidelines [11].

\section{Immunohistochemical assessment}

Liver cancer tissues were placed in paraformaldehyde and fixed for $24 \mathrm{~h}$. After dehydration and transparency, paraffin embedding was carried out. The thickness of continuous section was 4 to $6 \mathrm{~mm}$. During the test, xylene was used for dewaxing, ethanol was used for dehydration, while $3 \%$ hydrogen peroxide solution was used to block endogenous peroxidase activity. The slices were heated in citrate buffer, $\mathrm{pH} 6$ for 30 min, and incubated with $5 \%$ BSA for $45 \mathrm{~min}$, followed by incubation with antibodies against p-AKT, HMGB1 and MMP9 (Santa Cruz Biotechnology, USA) overnight at 4 ${ }^{\circ} \mathrm{C}$. Then, secondary antibody was added and incubation was continued at $37{ }^{\circ} \mathrm{C}$ for $45 \mathrm{~min}$, after which the sections were stained with $\mathrm{H}$ \& $\mathrm{E}$.

\section{Immunofluorescence assay}

The hepatocarcinoma cells were seeded in 12well plates for EP treatment [half inhibitory concentration $\left.\left(\mathrm{IC}_{50}\right)\right]$ or physiological saline for 2 days, and divided into sham group and $\alpha$-MMC group. The cells were plated on gelatin-coated coverslips, fixed with $4 \%$ paraformaldehyde, and rinsed 3 times with PBS, each rinse for $5 \mathrm{~min}$. Then, the cells were blocked with $1 \%$ BSA for 1 $\mathrm{h}$ at $37{ }^{\circ} \mathrm{C}$ and incubated overnight with primary antibodies. They were then washed 3 times with PBS, and incubated with secondary antibody at $37^{\circ} \mathrm{C}$ for $1 \mathrm{~h}$.

The cells were stained with 4', 6-diamidino-2phenylindole (DAPI) for $15 \mathrm{~min}$, and rinsed for 5 min. After mounting on glycerol, the cells were observed under a fluorescence microscope and photographed. The expressions of HMGB1 and MMP9 were observed under a fluorescence microscope.

\section{Statistics}

Data are expressed as mean $\pm \mathrm{SD}$, and were statistically analyzed using SPSS version 19.0. Independent sample $t$-test and LSD-t method were used for 2-group comparisons, while oneway ANOVA was used for multiple-group comparisons. Statistical significance was assumed at $p<0.05$. 


\section{RESULTS}

\section{$\alpha-M M C$ inhibited proliferation of liver cancer cells}

As shown Figure 1A, $\alpha$-MMC caused decreases in the survival of liver cancer cells (SMMC-7721, HepG2, HCC-LM3) in a dose-dependent manner. From MTT results, SMMC-7721 $(0.92 \mathrm{mg} / \mathrm{mL})$, HepG (21.24 $\mathrm{mg} / \mathrm{mL})$ and HCC-LM (31.06 $\mathrm{mg} / \mathrm{mL}$ ) were selected for subsequent experiments. After establishing a nude mouse model of liver cancer, $\alpha$-MMC was administered at a dose of 0.70 or $2.08 \mathrm{mg} / \mathrm{kg}$, and the mice were sacrificed 4 weeks later. The liver cancer of the treatment group was smaller than that of the control group (Figure 1D). After treatment, the diameter and volume of liver cancer cells were significantly decreased $(p<0.05$, Figures $1 \mathrm{~B}$ and $1 \mathrm{C})$. These results indicated that $\alpha$-MMC exerted anti-liver cancer effects.

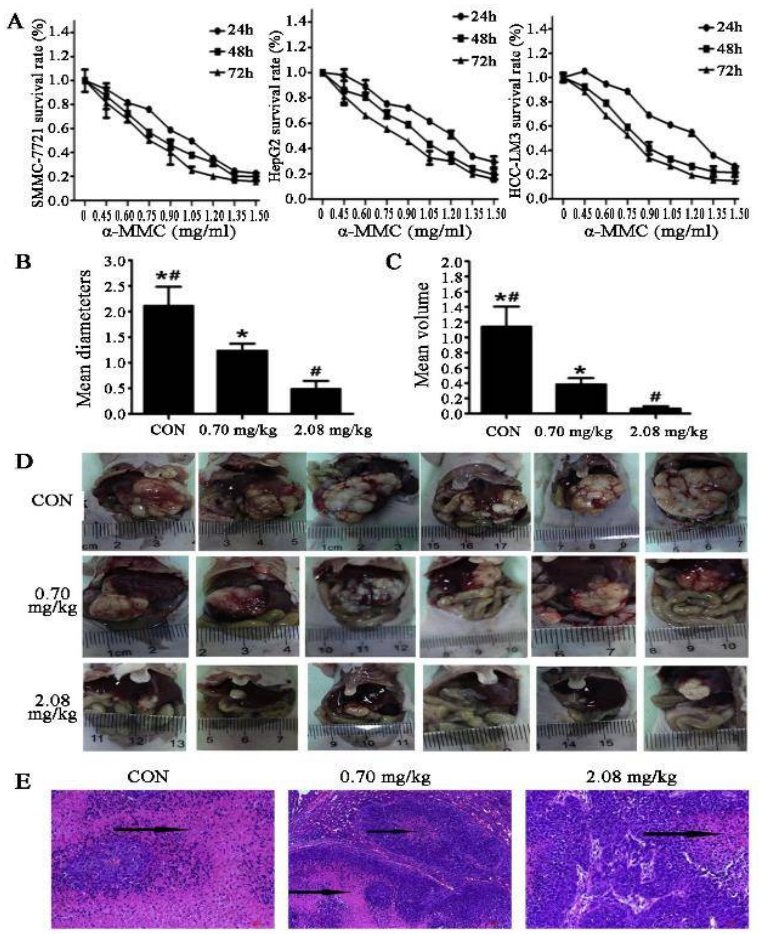

Figure 1: Results of in vivo and in vitro studies on the effect of $\alpha-M M C$ on hepatoma cell proliferation. (A) MTT assay for cell proliferation; (B) tumor diameter changes after injection of $\alpha$-MMC in nude mice; (C) tumor volume changes after injection of $\alpha$-MMC in nude mice; (D) H \& E staining showing liver cancer tissue structure $(\times 200)$

\section{a-MMC arrested liver cancer cell cycle and induced apoptosis}

As shown in Figure 2A, in HepG2 cells, $\alpha$-MMC at a dose of $1.24 \mathrm{mg} / \mathrm{mL}$ for $48 \mathrm{~h}$ interfered with the cell cycle at G2/M phase; whereas at doses of 0.92 and $1.06 \mathrm{mg} / \mathrm{mL}, \alpha-\mathrm{MMC}$ arrested the cell cycle of the other two cell lines at G0/G1 phase. As shown in Figure 2B, the proportion of early apoptosis and the proportion of late apoptosis increased after $\alpha$-MMC treatment $(p<0.05)$. There was an increase in the ratio of BAX/BCL2 in the hepatoma cell line after $\alpha$-MMC treatment $(p<0.05$, Figure $2 \mathrm{C}$ and Figure 2D). In in vivo studies, TUNNEL staining, RT-PCT, and western-blotting assays showed increased apoptosis in hepatoma cells after $\alpha$-MMC exposure (Figure 3).

\section{a-MMC inhibited HMGB1-RACE and AKT signal routes}

Results showed that $\alpha$-MMC significantly reduced the expression levels of HMGB1, RAGE and MMP9 genes $(p<0.05$, Figure 4A). The results of Western-blotting assay showed that $\alpha$ MMC significantly downregulated protein expressions of RAGE, HMGB1, MMP9 and PAKT $(p<0.05$, Figure 4B). In addition, immunofluorescence assay showed that $\alpha$-MMC downregulated the expressions of HMGB1 and MMP9 (Figure 4C). The results were similar in vivo (Figures 3C-3E).

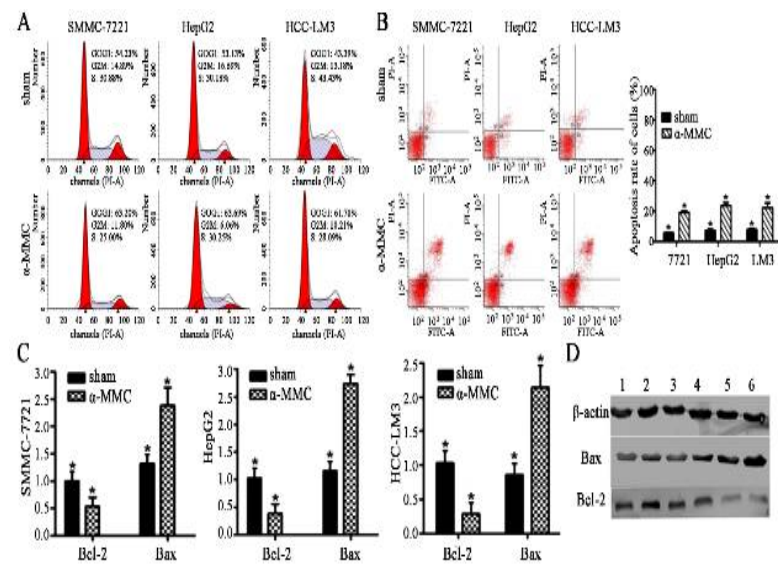

Figure 2: In vitro effect of $\alpha$-MMC on hepatoma cell cycle and apoptosis. (A) $\alpha-M M C$ caused cell cycle arrest in different stages of cell cycle in different liver cancer cells; (B) $\alpha$-MMC induced apoptosis of hepatoma cells, and flow cytometric analysis of the hepatoma cell lines with Annexin-V/ PI staining showed that the proportion of cells in early apoptosis and late apoptosis increased after $\alpha$-MMC intervention; (C) results of RT-PCR on the effect of $\alpha$ $\mathrm{MMC}$ on $\mathrm{Bcl} 2$ and Bax gene expression levels in vitro; (D) $\mathrm{Bcl} 2$ and Bax expression levels as determined with Western blotting. 1: SMMC-7721 dealt with normal saline; 2: HepG2 dealt with normal saline; 3: HCCLM3 dealt with normal saline; 4: SMMC-7721 treated with $0.92 \mathrm{mg} / \mathrm{mL} \alpha-\mathrm{MMC}$; 5 : HepG2 treated with 1.24 $\mathrm{mg} / \mathrm{mL} \alpha$-MMC; 6: HCC-LM3 treated with $1.06 \mathrm{mg} / \mathrm{mL}$ $\alpha-\mathrm{MMC}$

Trop J Pharm Res, September 2019; 18(9): 1938 


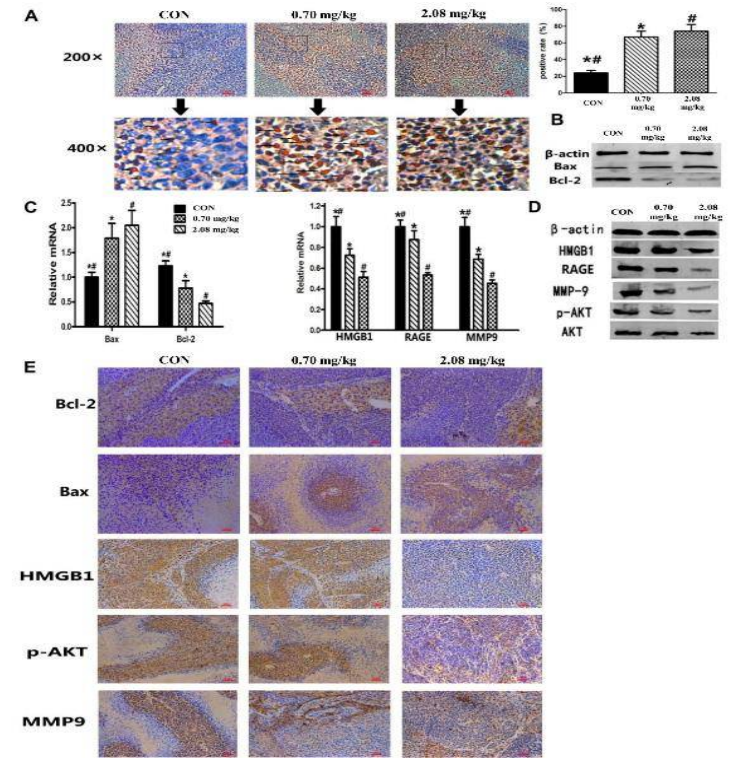

Figure 3: Results of in vivo studies on the effect of $\alpha$ MMC. (A) TUNNEL staining showed that $\alpha$-MMCinduced apoptosis of hepatocarcinoma cells in three groups of nude mice; (B) Western blotting results on the effect of $\alpha$-MMC on the expressions of Bcl-2 and Bax in liver cancer tissues; (C) RT-PCR results on the effect of $\alpha$-MMC on expressions of the various genes; (D) levels of expression of RAGE, HMGB1, AKT, MMP9, and p-AKT; (E) immunohistochemical results of the levels of Bax, Bcl-2, p-AKT, HMGB1, and MMP9 in the cancer tissues $(\times 200)$

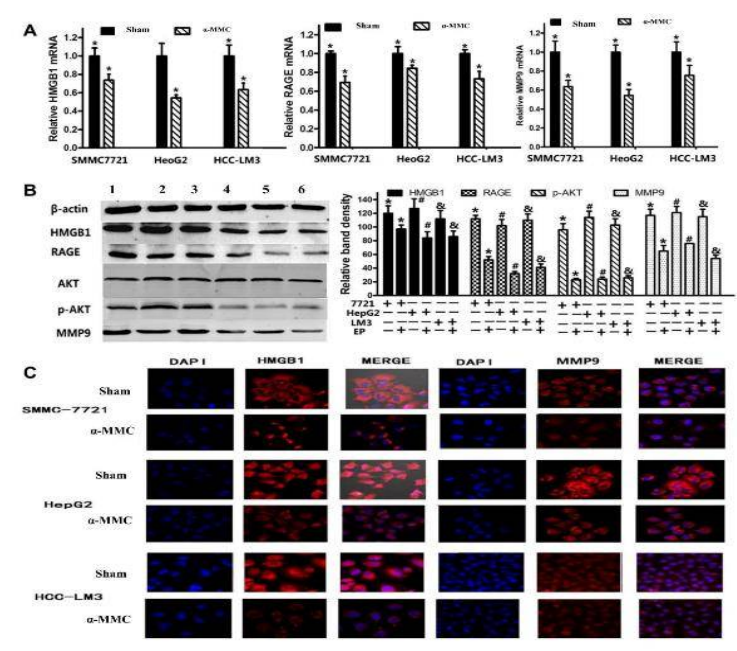

Figure 4: Effect of $\alpha-M M C$ on the HMGB1-RACE and AKT signaling pathways. (A) HMGB1, RAGE and MMP9 gene expressions in hepatoma cells; (B) Western-blotting was used to determine the expression levels of HMGB1, RAGE, P-AKT and MMP9 in hepatoma cells in vitro. 1: SMMC-7721 treated with normal saline; 2: HepG2 treated with normal saline; 3: HCC-LM3 treated with normal saline; 4: SMMC-7721 treated with $0.92 \mathrm{mg} / \mathrm{mL} \alpha-\mathrm{MMC}$; 5: HepG2 treated with $1.24 \mathrm{mg} / \mathrm{mL} \alpha$-MMC; HCC-LM3 treated with $1.06 \mathrm{mg} / \mathrm{mL} \quad \alpha-\mathrm{MMC}$; (C) results of immunofluorescence for the expression levels of HMGB1 and MMP9 in hepatoma cells $(\times 200)$

\section{DISCUSSION}

Liver cancer is a common malignant tumor in the digestive system. $\alpha$-Momordicine $(\alpha-\mathrm{MMC})$ is a type I ribosome-inactivating protein which is extracted from bitter gourd seeds. It modifies the ribosome subunit of ribosomal RNA, thereby inhibiting protein synthesis. Studies have shown that $\alpha$-MMC has anti-AIDS, anti-tumor and antifertility effects, but large doses of $\alpha$-MMC impair the immune system when used in animal therapy [12]. Therefore, the present study used medium and low doses of $\alpha$-MMC on liver cancer cells and nude mice in accordance with previous studies $[6,10]$.

It has been reported in in vivo and in vitro studies on breast cancer that $\alpha$-MMC has anticancer effects which result in inhibition of the proliferation, and induction of apoptosis of cancer cells [4]. This study found that $\alpha$-MMC showed anti-liver cancer effects by inhibiting proliferation and inducing apoptosis. Flow cytometry and MTT results revealed that HCC proliferation was inhibited after $48 \mathrm{~h}$ treatment with $\alpha$-MMC, which also induced apoptosis and cell cycle arrest. In in vivo studies, $H$ \& $E$ staining and TUNNEL staining also confirmed the anti-tumor property of $\alpha$-MMC.

The molecular mechanism involved in the growth-inhibiting effect of liver cancer cells by of $\alpha$-MMC is not yet clear. HMGB1-RACE and AKT signaling pathways are closely related to the occurrence of multifarious cancers such NSCLC, hepatoma and skin squamous cell carcinoma [13-15]. Studies have found that HMGB1 expression level is related to the clinical staging of liver cancer, suggesting that HMGB1 may be a marker of liver cancer. Targeted treatment of HMGB1 gene may contribute to the treatment of liver cancer [16]. The over-expression of RAGE, a membrane receptor which is expressed in many cell membranes, has been reported in several cancers and tumor-related tissues [17].

Previous studies have confirmed that blocking the HMGB1-RAGE pathway inhibits the occurrence of gastric cancer [18]. In addition, abnormal expression of AKT is associated with tumor growth and proliferation. The levels of AKT and p-AKT are elevated in HCC tissues and can help predict clinical outcomes in HCC patients [19]. In the present study, $\alpha-\mathrm{MMC}$ regulated the HMGB1-RAGE and AKT signaling pathways in liver cancer cells. There is an association between AKT-induced MMP9 and HMGB1 expression [20]. Down-regulation of MMP9 inhibits tumor cell proliferation and induces apoptosis [21]. The results of this study showed 
that $\alpha$-MMC downregulated the expression of MMP9 in liver cancer cells. When combined with RAGE, HMGB1 activated MMP9 and promoted tumor proliferation. Therefore, $\alpha$-MMC may play an important role in the treatment of liver cancer by down-regulating HMGB1 and RAGE. During apoptosis, Bax forms oligomers on the outer membrane of mitochondria.

In contrast, Bcl-2 inhibits mitochondrial apoptosis by blocking the Bax-induced oligomer formation. The results of this study showed disturbance in the Bax: Bcl2 ratio in HCC cells, with increased expression of Bax and decreased expression of $\mathrm{Bcl} 2$ due to treatment with $\alpha-\mathrm{MMC}$. Flow cytometry results showed that the proportions of early apoptosis (quadrant 2) and late apoptosis (quadrant 3) increased after treatment with $\alpha$ MMC. Thus, it can be reasonably speculated that $\alpha$-MMC exerts anti-liver cancer effect by regulating $\mathrm{Bax} / \mathrm{Bcl} 2$ ratio.

\section{CONCLUSION}

This study found that $\alpha$-MMC, an HMGB1 inhibitor, restrains the proliferation of liver cancer cells, and promotes their apoptosis by positively regulating the ratio of $\mathrm{Bax} / \mathrm{Bcl} 2$. Moreover, this study has shown that the anti-liver cancer effect of $\alpha-\mathrm{MMC}$ is mediated through the HMGB1RAGE and AKT signaling pathway. Thus, $\alpha$ MMC may be a potential drug for treating liver cancer but further investigations are required to confirm this.

\section{DECLARATIONS}

\section{Conflict of interest}

No conflict of interest is associated with this work.

\section{Contribution of authors}

We declare that this work was done by the author(s) named in this article and all liabilities pertaining to claims relating to the content of this article will be borne by the authors. All authors read and approved the manuscript for publication. Guan Chunfeng conceived and designed the study, Yang Mei, Jin Wen, Shi Wei, Wang Bo, Li Qing, Guan Chunfeng collected and analyzed the data. Yang Mei wrote the manuscript.

\section{Open Access}

This is an Open Access article that uses a funding model which does not charge readers or their institutions for access and distributed under the terms of the Creative Commons Attribution License (http://creativecommons.org/licenses/by/ 4.0) and the Budapest Open Access Initiative (http://www.budapestopenaccessinitiative.org/rea d), which permit unrestricted use, distribution, and reproduction in any medium, provided the original work is properly credited.

\section{REFERENCES}

1. da Motta Girardi D, Correa TS, Crosara Teixeira M, Dos Santos Fernandes G. Hepatocellular carcinoma: review of targeted and immune therapies. J Gastrointest Cancer 2018; 49(3): 227-236.

2. Desai A, Sandhu S, Lai JP, Sandhu DS. Hepatocellular carcinoma in non-cirrhotic liver: $A$ comprehensive review. World J Hepatol 2019 11(1): 1-18.

3. Tan MJ, Cao XW, Li PF, Zhai YZ, Zhou Y, Liu YJ, Zhao $J$, Wang FJ. Effectively enhancing cytotoxic and apoptotic effects of alpha-momorcharin by integrating a heparin-binding peptide. Biotechnol Appl Biochem 2017; 64(6): 918-926.

4. Cao $D$, Sun $Y$, Wang L, He Q, Zheng J, Deng F, Deng $S$, Chang S, YU X, Li M, et al. Alpha-momorcharin (alpha$M M C$ ) exerts effective anti-human breast tumor activities but has a narrow therapeutic window in vivo. Fitoterapia 2015; 100(1): 139-149.

5. Manoharan G, Jaiswal SR, Singh J. Effect of $\alpha, \beta$ momorcharin on viability, caspase activity, cytochrome $c$ release and on cytosolic calcium levels in different cancer cell lines. Mol Cell Biochem 2015; 388(1-2): 233240.

6. Bian $X$, Shen $F$, Chen $Y$, Wang $B$, Deng $M$, Meng $Y$. PEGylation of alpha-momorcharin: synthesis and characterization of novel anti-tumor conjugates with therapeutic potential. Biotechnol Lett 2010; 32(7): 883890.

7. Deng NH, Shen FB, Zheng JC, Shen D, Wang L. Study on the Mechanism of a-momordicin Inducing Early Apoptosis of Hepatocyte L02 via LRP1-mediated JNK Signaling Pathway. Chin Pharm 2018; 29(23): 40-44.

8. Chen RC, Yi PP, Zhou RR, Xiao MF, Huang ZB, Tang $D L$, Huang $Y$, Fan XG. The role of HMGB1-RAGE axis in migration and invasion of hepatocellular carcinoma cell lines. Mol Cell Biochem 2014; 390(1-2): 271-280.

9. Jiang J, Chen $Y$, Dong $T$, Yue $M$, Zhang $Y$, An T, Zhang $J$, Liu $P$, Yang $X$. Polydatin inhibits hepatocellular carcinoma via the AKT/STAT3-FOXO1 signaling pathway. Oncol Lett 2019; 17(5): 4505-4513.

10. Meng Y, Liu B, Lei N, Zheng J, He Q, Li D, Zhao X, Shen $F$. Alpha-momorcharin possessing high immunogenicity, immunotoxicity and hepatotoxicity in $S D$ rats. J Ethnopharmacol 2012; 139(2): 590-598.

11. Olsson IAS, Silva SPD, Townend $D$, et al. Protecting Animals and Enabling Research in the European Union: An Overview of Development and Implementation of Directive 2010/63/EU. ILAR J, 2016, 57(3):347-357.

Trop J Pharm Res, September 2019; 18(9): 1940 
12. Deng $N$, Sun $Y$, Liu $M$, He $Q$, Wang $L$, Zhang $Y$, Sun $W$, Lei $N$, Liu $Y$, Luo $Y$, et al. Alpha-momorcharin regulates cytokine expression and induces apoptosis in monocytes. Immunopharmacol Immunotoxicol 2019; 41(2): 258-266.

13. Lu L, Zhang D, Xu Y, Bai G, Lv Y, Liang J. miR-505 enhances doxorubicin-induced cytotoxicity in hepatocellular carcinoma through repressing the Akt pathway by directly targeting HMGB1. Biomed Pharmacother 2018; 104(1): 613-621.

14. Sun $Y$, Tu Y, He LI, Ji C, Cheng BO. High mobility group box 1 regulates tumor metastasis in cutaneous squamous cell carcinoma via the PIBK/AKT and MAPK signaling pathways. Oncol Lett 2016; 11(1): 59-62.

15. Chen $Y$, Zhou $X$, Qiao J, Bao A. MiR-142-3p Overexpression Increases Chemo-Sensitivity of NSCLC by Inhibiting HMGB1-Mediated Autophagy. Cell Physiol Biochem 2017; 41(4): 1370-1382.

16. Kohles $N$, Nagel $D$, Jungst $D$, Stieber $P$, Holdenrieder $S$. Predictive value of immunogenic cell death biomarkers HMGB1, SRAGE, and DNase in liver cancer patients receiving transarterial chemoembolization therapy. Tumour Biol 2012; 33(6): 2401-2409.
17. Ahmad S, Khan H, Siddiqui Z, Khan MY, Rehman S, Shahab U, Godovikova T, Silnikov V, Moinuddin M. AGEs, RAGEs and S-RAGE; friend or foe for cancer. Semin Cancer Biol 2018; 49(1): 44-55.

18. Zhang J, Zhu J-S, Zhou Z, Chen WX, Chen NW. Inhibitory effects of ethyl pyruvate administration on human gastric cancer growth via regulation of the HMGB1-RAGE and Akt pathways in vitro and in vivo. Oncol Rep 2012; 27(5): 1511-1519.

19. Tang $Y$, Wang R, Zhang $Y$, Lin S, Qiao N, Sun Z, Cheng $S$, Zhou W. Co-upregulation of $14-3-3 \zeta$ and P-Akt is associated with oncogenesis and recurrence of hepatocellular carcinoma. Cell Physiol Biochem 2018; 45(3): 1097-1107.

20. Yan H, Zhu L, Zhang Z, Li H, Li P, Wang Y, Leng M. HMGB1-RAGE signaling pathway in pPROM. Taiwan $J$ Obstet Gynecol 2018; 57(2): 211-216.

21. Klassen LMB, Chequin A, Manica GCM, Biembengut IV, Toledo MB, Baura VA, de O Pedrosa F, Ramos EAS, Costa FF, et al. MMP9 gene expression regulation by intragenic epigenetic modifications in breast cancer. Gene 2018; 642(1): 461-466. 